\title{
On the growth of calcium tartrate tetrahydrate single crystals
}

\author{
X SAHAYA SHAJAN ${ }^{\dagger}$ and C MAHADEVAN* \\ Physics Research Centre, S.T. Hindu College, Nagercoil 629 002, India \\ ${ }^{\dagger}$ Department of Physics, Sivanthi Aditanar College, Pillayarpuram 629 501, India
}

MS received 23 February 2004; revised 29 May 2004

\begin{abstract}
Calcium tartrate single crystals were grown using silica gel as the growth medium. Calcium formate mixed with formic acid was taken as the supernatant solution. It was observed that the nucleation density was reduced and the size of the crystals was improved to a large extent compared to the conventional way of growing calcium tartrate crystals with calcium chloride. The role played by formate-formic acid on the growth of crystals is discussed. The grown crystals were characterized by atomic absorption spectroscopy (AAS), Xray diffraction analysis (XRD), microhardness measurement, Fourier transform infrared spectroscopy (FTIR), thermogravimetry (TG) and differential thermal analysis (DTA). The results obtained are compared with the previous work.
\end{abstract}

Keywords. Gel growth; calcium tartrate; FTIR; thermal studies; microhardness.

\section{Introduction}

Tartrate crystals are of considerable interest, particularly for basic studies of some of their interesting physical properties (Yadava and Padmanabhan 1973; Desai and Patel 1987; Gon 1990; Abdel-Kader et al 1991). Calcium tartrate tetrahydrate crystals are found to be orthorhombic with lattice parameters: $a=9.24 \pm 0.02 \AA, b=10.63 \pm 0.02 \AA$, $c=9.66 \pm 0.02 \AA$ and the space group, $P 22_{1} 2_{1} 2_{1}$ (Ambady 1968). For the growth of calcium tartrate crystals it is customary to diffuse calcium chloride solution into the gel charged with tartaric acid. It has been reported that (Sivanesan et al 1992; Henisch 1996) the size of calcium tartrate crystals growing in the gel did not improve even after applying nucleation control techniques like concentration programming and neutral gel methods.

Most of the earlier works (Henisch et al 1965; Armington et al 1967; Dennis and Henisch 1967) on pure calcium tartrate crystals were done with an aim of understanding the basic principles and the nature of crystal growth phenomenon, especially those involved in the gel technique. With an aim of controlling nucleation and improving the size, in the present study, we have grown pure calcium tartrate tetrahydrate single crystals using calcium formate mixed with formic acid as the supernatant solution. The grown crystals have been characterized by density measurement, AAS, XRD, microhardness measurement, FTIR, TG and DTA studies. The crystal growth and the role played by formate-formic acid are discussed.

\footnotetext{
*Author for correspondence
}

\section{Experimental}

\subsection{Crystal growth}

The test tube diffusion method (Henisch 1996) was employed to grow calcium tartrate single crystals in a gel medium. $0.5 \mathrm{M}$ sodium meta silicate $\left(\mathrm{Na}_{2} \mathrm{SiO}_{3} \cdot 9 \mathrm{H}_{2} \mathrm{O}\right)$ was titrated with $0.5 \mathrm{M}$ tartaric acid till the mixture attained the $\mathrm{pH}$ of $4 \cdot 2$. This gelling mixture was allowed to set in glass tubes of length, $200 \mathrm{~mm}$ and diameter, $25 \mathrm{~mm}$. The gel was set in about $48 \mathrm{~h}$. After a gel aging of one day, the supernatant solution was added over the set gel. The supernatant solution was a mixture of $0.5 \mathrm{M}$ calcium formate and $85 \%$ formic acid so that the $\mathrm{pH}$ of the solution was between 1 and $1 \cdot 5$. The expected chemical reaction was

$$
\mathrm{Ca}(\mathrm{HCOO})_{2}+\mathrm{C}_{4} \mathrm{H}_{6} \mathrm{O}_{6} \rightarrow \mathrm{CaC}_{4} \mathrm{H}_{4} \mathrm{O}_{6}+2 \mathrm{HCOOH} \text {. }
$$

Small crystals appeared down the gel solution interface in about 2 days and large crystals with good morphological perfection appeared down the gel column within a week. The crystals were harvested after a month. The maximum size of the crystals grown was about $8 \times 6 \times 3 \mathrm{~mm}^{3}$. A photograph of the crystals growing inside the test tube is shown in figure 1.

\subsection{Density and microhardness}

The density of the crystal was found using flotation method. The hardness of the crystals was obtained using Leitz Weitzier hardness tester at room temperature. The static indentation was done on the crystals by applying load varying from 5 to $50 \mathrm{~g}$ over a fixed interval of $10 \mathrm{~s}$ and 
removed. For each load $(P)$, five impressions were made and the average of diagonal lengths $(d)$ of the indentation mark was obtained.

The Vicker's hardness number $\left(H_{\mathrm{v}}\right)$ was calculated using the formula

$$
H_{\mathrm{v}}=1.8544 P / d^{2}
$$

where $P$ is in $\mathrm{kg}, d$ is in $\mathrm{mm}$ and $H_{\mathrm{v}}$ is in $\mathrm{kg} / \mathrm{mm}^{2}$.

\subsection{AAS and XRD studies}

The AAS studies were carried out using Perkin Elmer spectrophotometer. The atomic concentrations of $\mathrm{Na}, \mathrm{Si}$ and $\mathrm{Fe}$ were determined in order to check the degree of purity of the grown crystals. The powder X-ray diffraction data were collected using JEOL-JDX 8030 X-ray diffractometer system available at the Central Electrochemical Research Institute, Karaikudi. The XRD pattern was used to identify the material and to determine the lattice parameters of the grown crystal.

\subsection{FTIR and thermal studies}

The FTIR spectrum of the grown crystals was recorded in the wavenumber range $400-4000 \mathrm{~cm}^{-1}$ using Centaurps

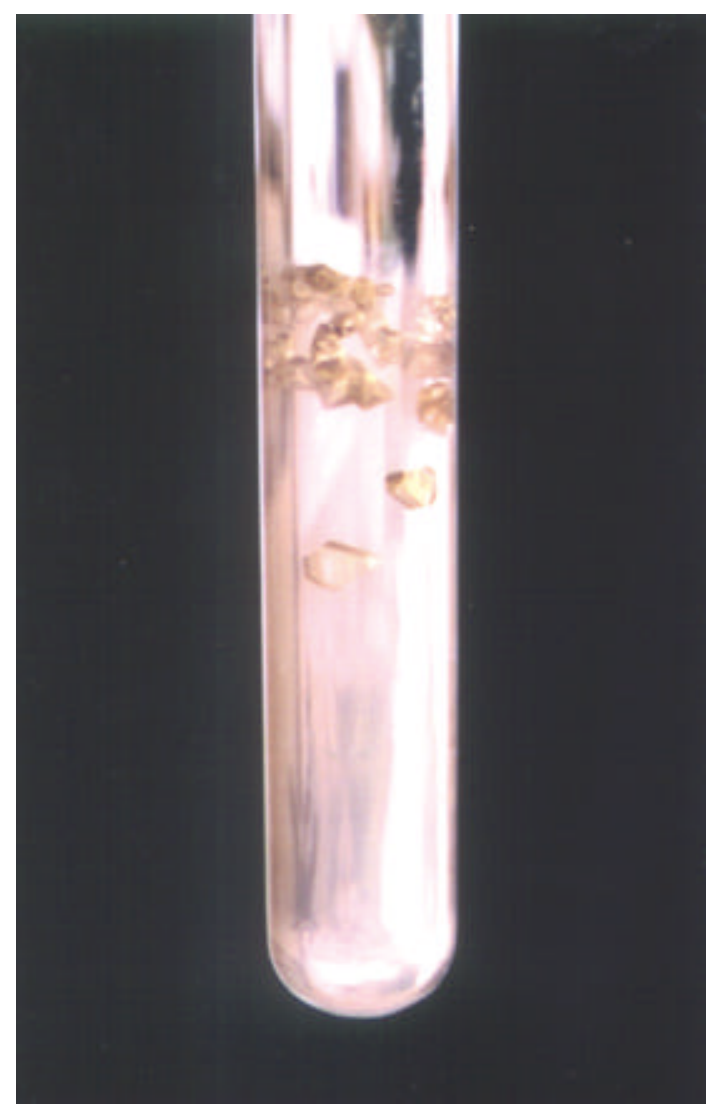

Figure 1. Growth of calcium tartrate single crystals in the test tube.
FTIR spectrometer. The thermogram of the crystal was obtained with the help of Seiko 320 thermal analyser. Thermogravimetric analysis was carried out from room temperature to $900^{\circ} \mathrm{C}$ at a heating rate of $10^{\circ} \mathrm{C}$ in the atmosphere of helium gas.

\section{Results and discussion}

\subsection{Crystal growth}

It has been reported that (Halberstadt and Henisch 1968) calcium tartrate does not nucleate at $\mathrm{pH}$ values $<3$. Also, during the growth of calcium tartrate crystals, the original tartaric acid content of the gel is completely exhausted partly through the formation of calcium tartrate crystals and partly through the demonstrable loss of tartaric acid to the solution at the top in the gel region close to the supernatant liquid. Normally, many small crystals grow in the gel medium and only a few of them are larger in size.

In order to suppress the nucleation and to improve the size of calcium tartrate crystals it is essential to eliminate the factors said above. We have tried to eliminate the first factor by using a suitable $\mathrm{pH}$ buffer and the second factor by acidifying the supernatant solution. Earlier works (Cipanov et al 1990) have shown that the variation of the acidity of the crystallogenetic media strongly influenced the depth of the first crystal arising in the gel. They have used calcium chloride mixed with hydrochloric acid as the supernatant solution. The nucleation suppression is achieved by converting the tartrate ions $\left(\mathrm{C}_{4} \mathrm{H}_{4} \mathrm{O}_{6}^{2-}\right)$ present near the gel solution interface into its molecular form $\left(\mathrm{H}_{2} \mathrm{C}_{4} \mathrm{H}_{4} \mathrm{O}_{6}\right)$ by proton introduction.

It was observed that the nucleation suppression near the gel solution interface was high when a strong acid, like $\mathrm{HCl}$, was used. On the other hand, when a weak acid like formic acid was used, we observed that nucleation suppression was very high. The first crystal arising in the gel when $\mathrm{HCl}$ was used was about one inch deep into the gel, whereas it was $2-3 \mathrm{~mm}$ when formic acid was used. However, considering the size and perfection of the grown crystals we found that those crystals grown by using formate-formic acid as the supernatant solution were superior to those crystals grown with calcium chloride- $\mathrm{HCl}$. Most of the crystals were larger in size and few crystals very close to the gel solution interface were smaller in size. The average length of the grown crystals was found to be $5 \cdot 2 \mathrm{~mm}$.

The growth veils reported by earlier workers (Armington et al 1967; Henisch 1996) are absent in the crystals grown by using formate-formic acid as the supernatant solution (figure 2 illustrates the absence of veils). It is expected that formate/formic acid acts as a $\mathrm{pH}$ buffer and maintains the $\mathrm{pH}$ of the gel medium throughout the growth process. Hence, the crystals growing deep into the gel are larger in size. In addition, formic acid prevents algae growth 
which disturbs the growth of calcium tartrate crystals during long growth periods.

\subsection{Density and mean mass of the grown crystal}

The density of the crystal was found to be $1.817 \mathrm{~g} / \mathrm{cc}$. This value agrees well with the reported values of 1.836 and $1.818 \mathrm{~g} / \mathrm{cc}$ (Armington et al 1967; Jesu Rethinam 1993). The mean mass of the grown crystals was found to be $92.8 \mathrm{mg}$ when the $\mathrm{pH}$ of the supernatant solution was 1.0 and $81.3 \mathrm{mg}$ when $\mathrm{pH}$ was $1 \cdot 3$. For the crystals grown from calcium chloride mixed with $\mathrm{HCl}$, it was reported that (Cipanov et al 1990) the mean mass was 39.4 and $46.5 \mathrm{mg}$ for $\mathrm{pH}=1 \cdot 08$ and $1 \cdot 3$, respectively.

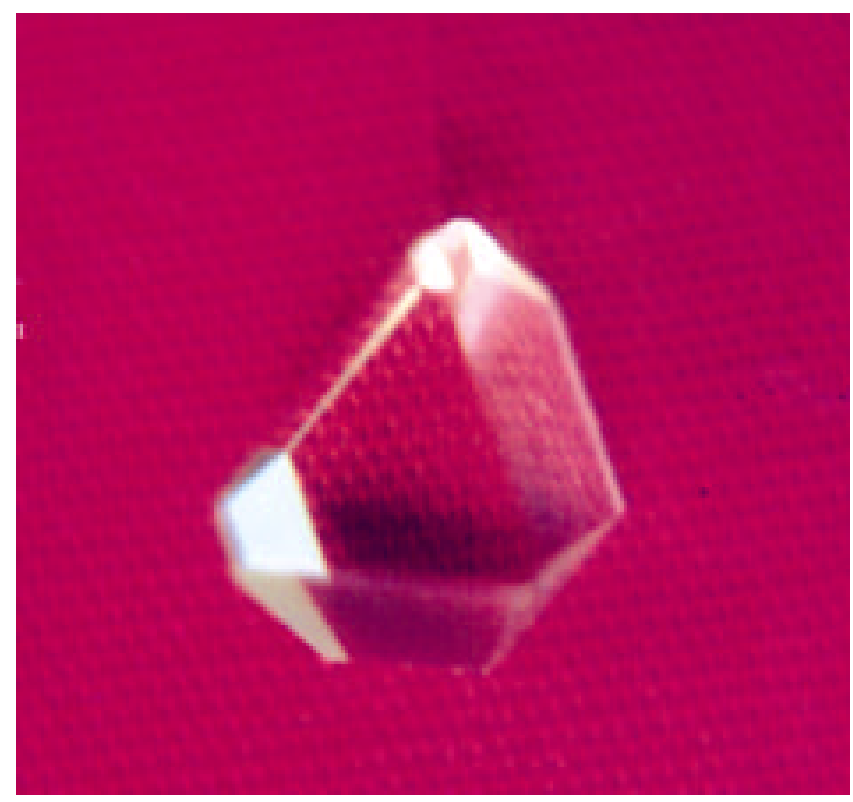

Figure 2. Photograph showing the absence of growth veils in the grown crystals.

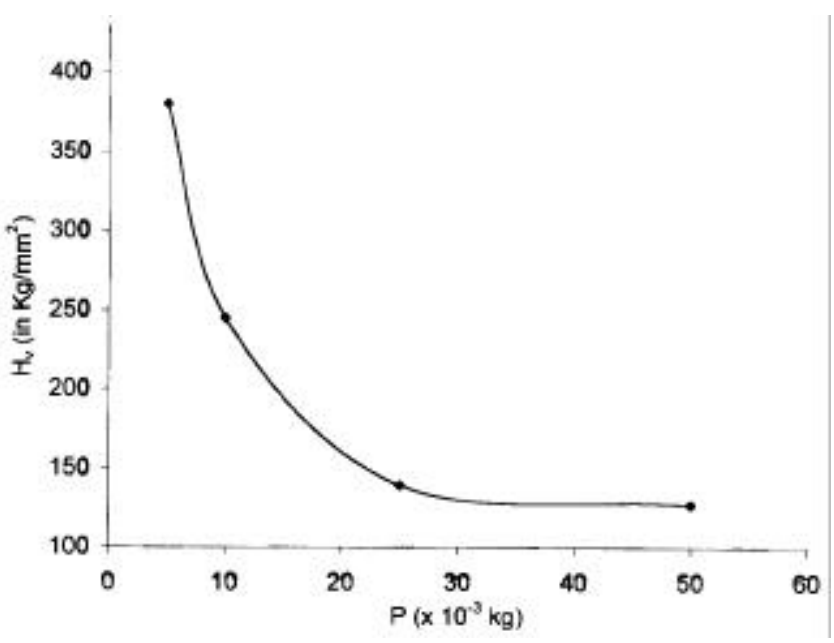

Figure 3. Variation of microhardness $\left(H_{\mathrm{v}}\right)$ with load $(P)$.

\subsection{Microhardness}

The values of $H_{\mathrm{v}}$ were calculated using (2) for various loads and are plotted as shown in figure 3. It was observed that the microhardness was found to decrease initially with increasing load and became constant at higher loads. During indentation, the indentor first penetrates the distorted zone of the surface layer. Therefore, we observe a decrease in the hardness of the material for increasing load. As the depth of indentation increases with load, the effect of the inner layers become more and more prominent than the surface layers and the indentor reaches a depth at which undistorted materials exist and therefore, no change is observed in the value of hardness with load.

The hardness obtained for the crystals grown in the present study using Leitz Weitzier hardness tester at room temperature for a $50 \mathrm{~g}$ load was $127 \mathrm{~kg} / \mathrm{mm}^{2}$. The hardness of calcium tartrate crystals available in the literature (Armington et al 1967) using Leitz Durimet microhardness tester with a knoop indentor for a $100 \mathrm{~g}$ load was $111.2 \mathrm{~kg} / \mathrm{mm}^{2}$.

We have determined the work hardening coefficient, $n$, from the slope of $\log P$ vs $\log d$ plot (not shown) using least square fit method. The value of $n$ was found to be $<2$. According to theory (Onitsch 1947), if $n<2$, the materials are said to be hard ones. He also found that microhardness decreases with increasing load when $n<2$ and increases with load when $n>2$. The decrease in $H_{\mathrm{v}}$ for increasing load, $P$, observed in the present study is in good agreement with the theoretical prediction and calcium tartrate crystals grown in the present study fall in the category of hard materials.

\subsection{AAS and XRD studies}

The atomic concentrations obtained by AAS in the grown crystals were $1 \cdot 167,11.834$ and 2 ppm for Fe, $\mathrm{Na}$ and $\mathrm{Si}$, respectively. Trace atomic concentrations of $\mathrm{Na}$ and $\mathrm{Si}$ show that the grown crystal was not contaminated by the gel. The atomic concentration of Fe was determined be-

Table 1. Indexed XRD data for calcium tartrate tetrahydrate crystals.

\begin{tabular}{lcrlcr}
\hline & \multicolumn{2}{c}{ From present work } & & \multicolumn{2}{c}{ From JCPDS file } \\
\cline { 2 - 3 } \cline { 5 - 6 }$h k l$ & $2 \theta\left(^{\circ}\right)$ & $I / I_{0}$ & & $2 \theta\left(^{\circ}\right)$ & $I / I_{0}$ \\
\hline 101 & $13 \cdot 4$ & 100 & & $13 \cdot 283$ & 100 \\
020 & $16 \cdot 9$ & 66 & & $16 \cdot 777$ & 35 \\
200 & $18 \cdot 5$ & 58 & & $18 \cdot 430$ & 35 \\
121 & $21 \cdot 5$ & 44 & & $21 \cdot 446$ & 20 \\
122 & $27 \cdot 2$ & 35 & & $27 \cdot 275$ & 10 \\
301 & $29 \cdot 5$ & 43 & & $29 \cdot 454$ & 40 \\
321 & $34 \cdot 0$ & 29 & & $34 \cdot 088$ & 18 \\
041 & $35 \cdot 5$ & 69 & & $35 \cdot 336$ & 55 \\
232 & $37 \cdot 0$ & 23 & & $37 \cdot 104$ & 4 \\
223 & $38 \cdot 7$ & 23 & & $38 \cdot 696$ & 8 \\
\hline
\end{tabular}


cause the starting materials used in the present work had a slightly higher ppm level of Fe compared to other elements in it.

XRD has confirmed the material of the grown crystals. The indexed XRD data for the grown crystals are given in table 1 . The diffraction data match very well with the JCPDS data for calcium tartrate tetrahydrate crystals. The lattice parameters obtained in the present study are: $a=9 \cdot 227$ (13), $b=10 \cdot 622(28), c=9 \cdot 652(8) \AA$ which compares very well with the reported lattice parameters (Ambady 1968).

\subsection{FTIR and thermal studies}

The FTIR spectrum of the grown crystals recorded in the wavenumber range $400-4000 \mathrm{~cm}^{-1}$ is shown in figure 4 . The two strong peaks at 3565 and $3425 \mathrm{~cm}^{-1}$ are due to $\mathrm{OH}$ stretching mode and to water. The band at $1588 \mathrm{~cm}^{-1}$ is attributed to the $\mathrm{C}=\mathrm{O}$ stretch of carbonyl group. The strong peak at $1385 \mathrm{~cm}^{-1}$ is assigned to $\mathrm{C}=\mathrm{O}$ symmetric and $\delta(\mathrm{O}-$ $\mathrm{C}=\mathrm{O}$ ) mode. The peak at 1148 is due to $\mathrm{C}-\mathrm{H}$ vibrational modes. The peaks of various intensities at 1061 and $1011 \mathrm{~cm}^{-1}$ are due to out of plane $\mathrm{O}-\mathrm{H}$ deformation and $\mathrm{C}-\mathrm{O}$ stretching. The absorption between $964 \mathrm{~cm}^{-1}$ and $534 \mathrm{~cm}^{-1}$ is due to calcium-oxygen. The FTIR spectrum obtained in the present study is similar to the IR spectrum of calcium tartrate crystals reported earlier (Selvarajan et al 1993; Vimal and Mihir 2001). The observed vibrational frequencies and their assignments are listed in table 2. FTIR spectrum revealed the presence of water molecules, $\mathrm{O}-\mathrm{H}$ bond, $\mathrm{C}-\mathrm{O}$ and carbonyl $\mathrm{C}=\mathrm{O}$ bonds.

The mechanical stiffness constant was calculated for $\mathrm{C}=\mathrm{O}$ vibration at $1588 \mathrm{~cm}^{-1}$ using the relation,

$$
\mathrm{v}=1303\left\{F\left(1 / m_{1}+1 / m_{2}\right)\right\}^{1 / 2}
$$

where $m_{1}=16$ a.m.u., $m_{2}=12$ a.m.u., $F$ the force constant and $v$ the stretching vibration. The value was found to be $1018 \mathrm{Nm}^{-1}$ which agrees very well with the reported value, $1020 \mathrm{Nm}^{-1}$ (Vimal and Mihir 2001).

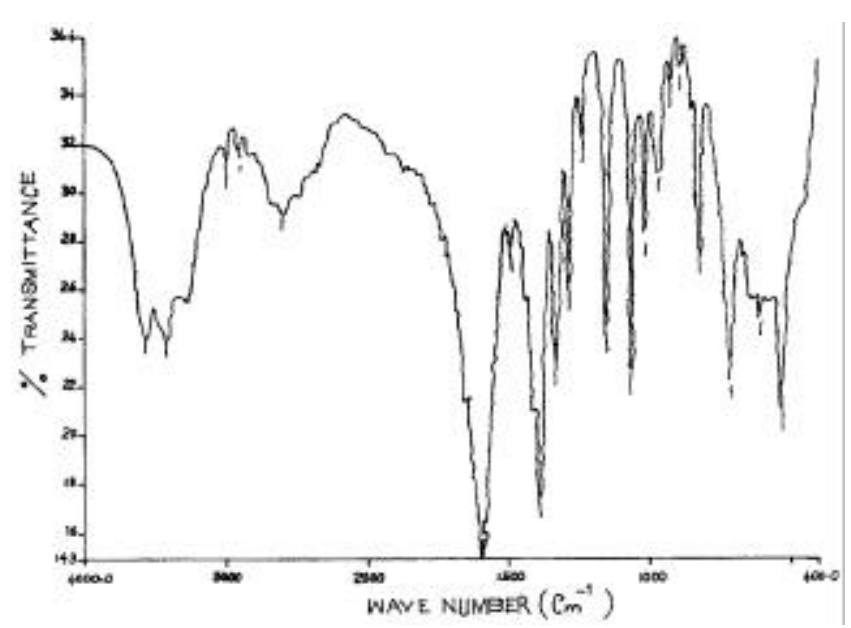

Figure 4. FTIR spectrum of calcium tartrate single crystals.
The TG, DTG and DTA thermograms of the grown crystals are shown in figure 5 . It is noticed that the sample loses water of hydration and becomes anhydrous at $192^{\circ} \mathrm{C}$ and thereafter it decomposes into calcium oxalate and further decomposes into calcium carbonate at $667^{\circ} \mathrm{C}$ and finally turns into calcium oxide at $807^{\circ} \mathrm{C}$ and remains stable up to the end of the analysis. It was estimated that four water molecules were associated with the crystals. In the DTA curve we observe two endothermic peaks at 164 and $290 \cdot 2^{\circ} \mathrm{C}$ and an exothermic peak at $438.8^{\circ} \mathrm{C}$.

Thermal studies showed that these crystals are thermally unstable beyond $112^{\circ} \mathrm{C}$ and there is no physical transformation independent of mass change or decomposition of calcium tartrate crystals. Thermal studies on calcium tartrate tetrahydrate crystals reported earlier (Selvarajan et al 1993) grown from calcium chloride showed that the crystals started decomposing at $85^{\circ} \mathrm{C}$ and finally decomposed into calcium oxide at $420^{\circ} \mathrm{C}$. However, in the present study we observed that the decomposition started at $112^{\circ} \mathrm{C}$ and decomposed finally into calcium oxide at $807^{\circ} \mathrm{C}$. This shows that the crystals grown in the present study are thermally more stable than the reported one.

Table 2. FTIR spectral data for calcium tartrate crystals.

\begin{tabular}{ll}
\hline Band $\left(\mathrm{cm}^{-1}\right)$ & \multicolumn{1}{c}{ Assignment } \\
\hline 3565 & OH stretching \\
3425 & OH stretch (water) \\
2987 & CH stretch \\
1588 & C=O stretch \\
1385 & $\gamma(\mathrm{C}=\mathrm{O})+\delta(\mathrm{O}-\mathrm{C}=\mathrm{O})$ \\
1330 & OH plane bending \\
1148 & $\delta(\mathrm{C}-\mathrm{H})+\pi(\mathrm{C}-\mathrm{H})$ \\
1061 & O-H deformation \\
1011 & C-O stretching \\
$964-534$ & Ca-O mode \\
\hline
\end{tabular}

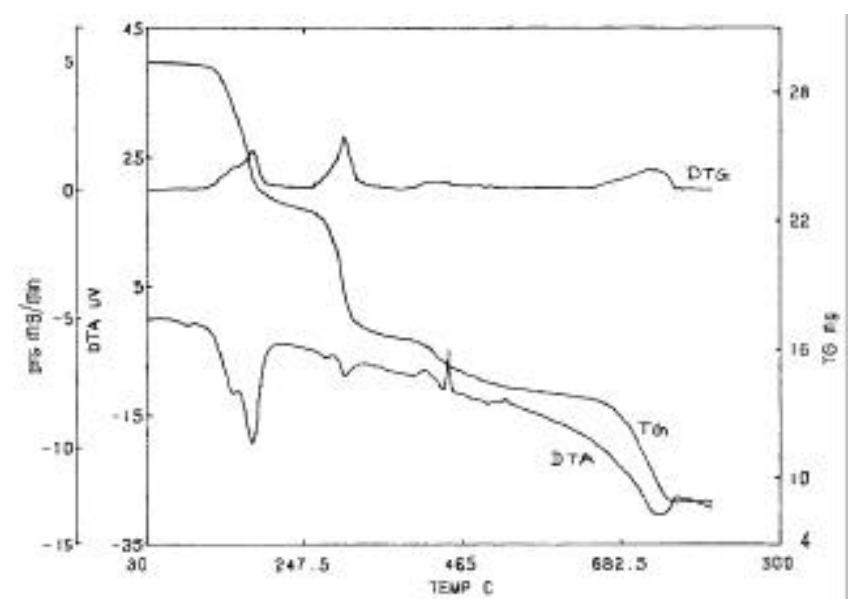

Figure 5. TG, DTG and DTA curves of calcium tartrate single crystals. 


\section{Conclusions}

Calcium tartrate crystals were grown in silica gel with calcium formate mixed with formic acid as supernatant solution. Nucleation was reduced and size of the crystals growing deep into the gel was improved a lot compared to the crystals grown with calcium chloride as supernatant solution. It is concluded that calcium tartrate crystals grown from formate-formic acid are better than the calcium tartrate crystals grown by other methods reported so far.

From microhardness measurements we conclude that the grown crystals belong to hard materials. XRD confirmed the material of the grown crystal to be calcium tartrate tetrahydrate. AAS studies confirmed that the crystals grown by this method was not contaminated by the gel.

The FTIR spectrum of the grown crystals revealed the presence of $\mathrm{O}-\mathrm{H}, \mathrm{C}-\mathrm{O}$ and $\mathrm{C}=\mathrm{O}$ bonds. The presence of water molecules were detected. From the thermogram it is concluded that calcium tartrate crystals are thermally unstable beyond $112^{\circ} \mathrm{C}$ and decomposes into calcium oxide through many stages.

\section{References}

Abdel-Kader M M, El-Kabbany F, Taha S, Abosehly M, Tahoon K K and El-Sharkawy A A 1991 J. Phys. Chem. Solids 52655
Ambady G K 1968 Acta Crystallogr. B24 1548

Armington A F, O'Connor J J and DiPietro M A 1967 AFCRL67-0304, Physical Sciences Research Papers, No. 325

Cipanov A V, Goshka L L and Ruzov V P 1990 Cryst. Res. Technol. 25737

Dennis J and Henisch H K 1967 J. Electrochem. Soc. 114 263

Desai C C and Patel A H 1987 J. Mater. Sci. Lett. 61066

Gon H B 1990 J. Cryst. Growth 102501

Halberstadt E S and Henisch H K 1968 J. Cryst. Growth 43 363

Henisch H K 1996 Crystal growth in gels (New York: Dover Publications Inc.) p. 20

Henisch H K, Hanoka J I and Dennis J 1965 J. Electrochem. Soc. 112627

Jesu Rethinam F 1993 Growth and characterization of pure and doped strontium tartrate single crystals, Ph.D. Thesis, University of Madras, Chennai

Onitsch E M 1947 Mikroskopie 2131

Selvarajan P, Das B N, Gon H B and Rao K V 1993 J. Mater. Sci. Lett. 121210

Sivanesan G, Selvasekarapandian S and Gnanam F D 1992 Cryst. Res. Technol. 271033

Vimal S Joshi and Mihir J Joshi 2001 Indian J. Phys. A75 159

Yadava V S and Padmanabhan V M 1973 Acta Crystallogr. B29 493 